This is the final peer-reviewed accepted manuscript of:

Giorgi G, Pirazzini C, Bacalini MG, Giuliani C, Garagnani P, Capri M, Bersani F, Del Re $B$. Assessing the combined effect of extremely low-frequency magnetic field exposure and oxidative stress on LINE-1 promoter methylation in human neural cells. Radiat Environ Biophys. 2017 May;56(2):193-200.PMID: 28258386

The final published version is available online at: $\mathrm{http}: / / \mathrm{dx}$. doi.org/10.1007/s00411-017-0683-8

Rights / License:

The terms and conditions for the reuse of this version of the manuscript are specified in the publishing policy. For all terms of use and more information see the publisher's website.

This item was downloaded from IRIS Università di Bologna (https://cris.unibo.it/)

When citing, please refer to the published version. 
Dear Author,

Here are the proofs of your article.

- You can submit your corrections online, via e-mail or by fax.

- For online submission please insert your corrections in the online correction form. Always indicate the line number to which the correction refers.

- You can also insert your corrections in the proof PDF and email the annotated PDF.

- For fax submission, please ensure that your corrections are clearly legible. Use a fine black pen and write the correction in the margin, not too close to the edge of the page.

- Remember to note the journal title, article number, and your name when sending your response via e-mail or fax.

- Check the metadata sheet to make sure that the header information, especially author names and the corresponding affiliations are correctly shown.

- Check the questions that may have arisen during copy editing and insert your answers/ corrections.

- Check that the text is complete and that all figures, tables and their legends are included. Also check the accuracy of special characters, equations, and electronic supplementary material if applicable. If necessary refer to the Edited manuscript.

- The publication of inaccurate data such as dosages and units can have serious consequences. Please take particular care that all such details are correct.

- Please do not make changes that involve only matters of style. We have generally introduced forms that follow the journal's style.

Substantial changes in content, e.g., new results, corrected values, title and authorship are not allowed without the approval of the responsible editor. In such a case, please contact the Editorial Office and return his/her consent together with the proof.

- If we do not receive your corrections within $\mathbf{4 8}$ hours, we will send you a reminder.

- Your article will be published Online First approximately one week after receipt of your corrected proofs. This is the official first publication citable with the DOI. Further changes are, therefore, not possible.

- The printed version will follow in a forthcoming issue.

\section{Please note}

After online publication, subscribers (personal/institutional) to this journal will have access to the complete article via the DOI using the URL: http://dx.doi.org/[DOI].

If you would like to know when your article has been published online, take advantage of our free alert service. For registration and further information go to: http://www.link.springer.com.

Due to the electronic nature of the procedure, the manuscript and the original figures will only be returned to you on special request. When you return your corrections, please inform us if you would like to have these documents returned. 


\section{Metadata of the article that will be visualized in OnlineFirst}

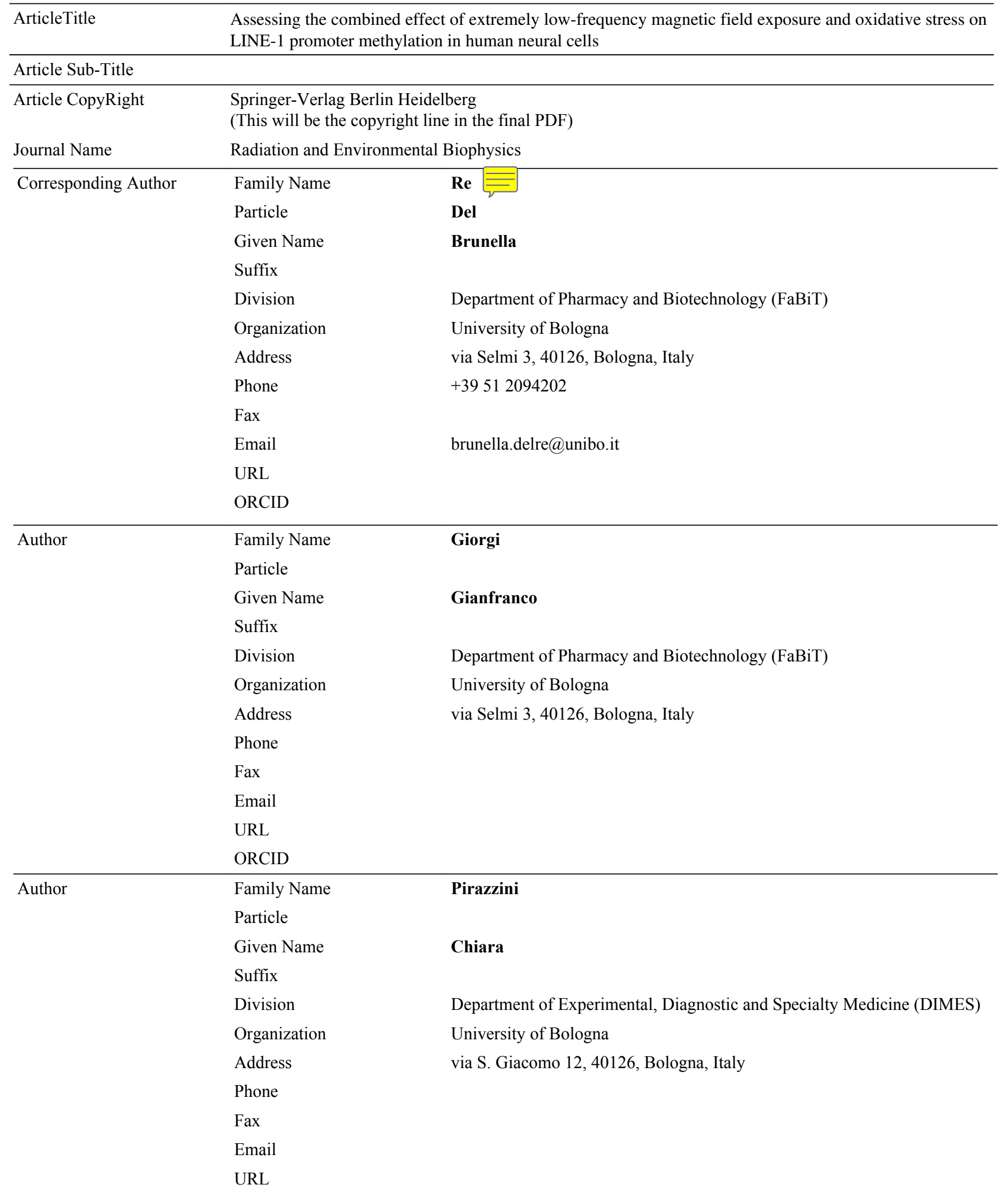




\begin{tabular}{|c|c|c|}
\hline \multirow[t]{12}{*}{ Author } & Family Name & Bacalini \\
\hline & Particle & \\
\hline & Given Name & Maria Giulia \\
\hline & Suffix & \\
\hline & Division & Department of Experimental, Diagnostic and Specialty Medicine (DIMES) \\
\hline & Organization & University of Bologna \\
\hline & Address & via S. Giacomo 12, 40126, Bologna, Italy \\
\hline & Phone & \\
\hline & Fax & \\
\hline & Email & \\
\hline & URL & \\
\hline & ORCID & \\
\hline \multirow[t]{12}{*}{ Author } & Family Name & Giuliani \\
\hline & Particle & \\
\hline & Given Name & Cristina \\
\hline & Suffix & \\
\hline & Division & $\begin{array}{l}\text { Department of Biological, Geological and Environmental Sciences } \\
\text { (BiGeA), Centre for Genome Biology }\end{array}$ \\
\hline & Organization & University of Bologna \\
\hline & Address & via Selmi 3, 40126, Bologna, Italy \\
\hline & Phone & \\
\hline & Fax & \\
\hline & Email & \\
\hline & URL & \\
\hline & ORCID & \\
\hline \multirow[t]{15}{*}{ Author } & Family Name & Garagnani \\
\hline & Particle & \\
\hline & Given Name & Paolo \\
\hline & Suffix & \\
\hline & Division & Department of Experimental, Diagnostic and Specialty Medicine (DIMES) \\
\hline & Organization & University of Bologna \\
\hline & Address & via S. Giacomo 12, 40126, Bologna, Italy \\
\hline & Division & \\
\hline & Organization & $\begin{array}{l}\text { CIG-Interdepartmental Centre "L. Galvani" for Bioinformatics, Biophysics } \\
\text { and Biocomplexity }\end{array}$ \\
\hline & Address & Piazza di Porta San Donato 1, 40126, Bologna, Italy \\
\hline & Phone & \\
\hline & Fax & \\
\hline & Email & \\
\hline & URL & \\
\hline & ORCID & \\
\hline \multirow[t]{4}{*}{ Author } & Family Name & Capri \\
\hline & Particle & \\
\hline & Given Name & Miriam \\
\hline & Suffix & \\
\hline
\end{tabular}




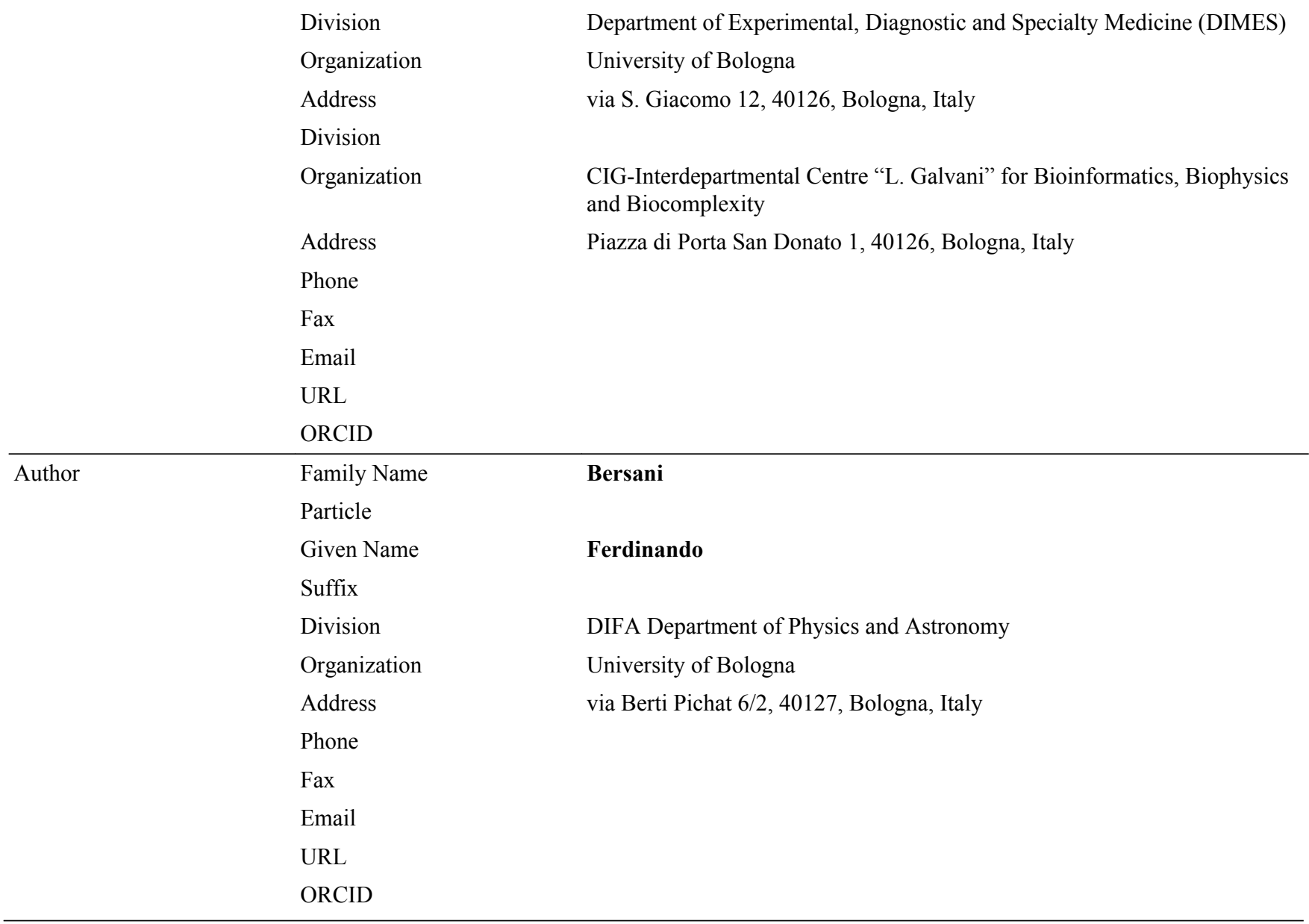

\begin{tabular}{lll}
\hline & Received & \\
\hline Revised & July 2016 \\
& Accepted & 11 January 2017 \\
\hline
\end{tabular}

Abstract

Extremely low frequency magnetic fields (ELF-MF) have been classified as "possibly carcinogenic", but their genotoxic effects are still unclear. Recent findings indicate that epigenetic mechanisms contribute to the genome dysfunction and it is well known that they are affected by environmental factors. To our knowledge, to date the question of whether exposure to ELF-MF can influence epigenetic modifications has been poorly addressed. In this paper, we investigated whether exposure to ELF-MF alone and in combination with oxidative stress (OS) can affect DNA methylation, which is one of the most often studied epigenetic modification. To this end, we analyzed the DNA methylation levels of the 5 'untranslated region $\left(5^{\prime} \mathrm{UTR}\right)$ of long interspersed nuclear element-1s (LINE-1 or L1), which are commonly used to evaluate the global genome methylation level. Human neural cells $(\mathrm{BE}(2) \mathrm{C})$ were exposed for 24 and $48 \mathrm{~h}$ to extremely low frequency pulsed magnetic field (PMF; $50 \mathrm{~Hz}, 1 \mathrm{mT})$ in combination with OS. The methylation levels of CpGs located in L1 5'UTR region were measured by MassARRAY EpiTYPER. The results indicate that exposures to the single agents PMF and OS induced weak decreases and increases of DNA methylation levels at different CpGs. However, the combined exposure to PMF and OS lead to significant decrease of DNA methylation levels at different CpG sites. Most of the changes were transient, suggesting that cells can restore homeostatic DNA methylation patterns. The results are discussed and future research directions outlined.

Keywords (separated by '-') DNA methylation - Epigenetics - LINE-1 - Retrotransposition - Extremely low frequency magnetic field Oxidative stress

Footnote Information $\quad$ Gianfranco Giorgi and Chiara Pirazzini are co-first authors. 


\title{
Assessing the combined effect of extremely low-frequency magnetic field exposure and oxidative stress on LINE-1 promoter methylation in human neural cells
}

\author{
Gianfranco Giorgi ${ }^{1}$ - Chiara Pirazzini ${ }^{2} \cdot$ Maria Giulia Bacalini $^{2} \cdot$ Cristina Giuliani $^{3}$. \\ Paolo Garagnani ${ }^{2,4} \cdot$ Miriam Capri $^{2,4} \cdot$ Ferdinando Bersani $^{5} \cdot$ Brunella Del Re $^{1}$
}

Received: 8 July 2016 / Accepted: 11 January 2017

(C) Springer-Verlag Berlin Heidelberg 2017

\begin{abstract}
Extremely low frequency magnetic fields (ELF-MF) have been classified as "possibly carcinogenic", but their genotoxic effects are still unclear. Recent findings indicate that epigenetic mechanisms contribute to the genome dysfunction and it is well known that they are affected by environmental factors. To our knowledge, to date the question of whether exposure to ELF-MF can influence epigenetic modifications has been poorly addressed. In this paper, we investigated whether exposure to ELF-MF alone and in combination with oxidative stress (OS) can affect DNA methylation, which is one of the most often studied epigenetic modification. To this end, we analyzed the DNA methylation levels of the 5'untranslated region ( $\left.5^{\prime} \mathrm{UTR}\right)$ of long interspersed nuclear element1s (LINE-1 or L1), which are commonly used to evaluate the global genome methylation level. Human neural cells (BE(2)C) were exposed for 24 and 48 h to extremely low
\end{abstract}

Gianfranco Giorgi and Chiara Pirazzini are co-first authors.

$\triangle$ Brunella Del Re

brunella.delre@unibo.it

1 Department of Pharmacy and Biotechnology (FaBiT), University of Bologna, via Selmi 3, 40126 Bologna, Italy

2 Department of Experimental, Diagnostic and Specialty Medicine (DIMES), University of Bologna, via S. Giacomo 12, 40126 Bologna, Italy

3 Department of Biological, Geological and Environmental Sciences (BiGeA), Centre for Genome Biology, University of Bologna, via Selmi 3, 40126 Bologna, Italy

4 CIG-Interdepartmental Centre "L. Galvani" for Bioinformatics, Biophysics and Biocomplexity, Piazza di Porta San Donato 1, 40126 Bologna, Italy

5 DIFA Department of Physics and Astronomy, University of Bologna, via Berti Pichat 6/2, 40127 Bologna, Italy frequency pulsed magnetic field (PMF; $50 \mathrm{~Hz}, 1 \mathrm{mT}$ ) in combination with OS. The methylation levels of CpGs located in L1 5'UTR region were measured by MassARRAY EpiTYPER. The results indicate that exposures to the single agents PMF and OS induced weak decreases and increases of DNA methylation levels at different CpGs. However, the combined exposure to PMF and OS lead to significant decrease of DNA methylation levels at different $\mathrm{CpG}$ sites. Most of the changes were transient, suggesting that cells can restore homeostatic DNA methylation patterns. The results are discussed and future research directions outlined.

Keywords DNA methylation · Epigenetics · LINE-1 · Retrotransposition · Extremely low frequency magnetic field $\cdot$ Oxidative stress

\section{Introduction}

Extremely low frequency magnetic fields (ELF-MF) are pervasive in today's society. Indeed, people are exposed to increasing electromagnetic fields generated by power lines and ordinary electric and electronic devices on a daily basis. In 2002, the International Agency for Research on Cancer surmised that ELF-MFs increase the risk of neoplastic malignancies and classified them as "possibly carcinogenic to humans" (IARC 2002).

Various in vivo and in vitro studies have been carried out to understand the molecular mechanisms behind the biological effects induced by ELF-MF, but a clear picture has not yet emerged. Moreover, the assessment of genotoxicity by standard genotoxicity assays has given conflicting results, so the question whether ELF-MF can be involved in carcinogenesis or in cancer progression is still unanswered 
(Vijayalaxmi and Prihoda 2009). Some reports suggested that ELF-MF exposure alone is not genotoxic but it can increase DNA damage in the presence of a genotoxic agent. Therefore, further research dealing with co-exposure evaluation should be considered.

Recent evidence suggests that non-genotoxic epigenetic mechanisms, such as DNA methylation, microRNA, long noncoding RNAs, histone code etc, are involved in aging and disease development and, in particular it is known that DNA methylation may play a key role in tumorigenesis and tumor progression (Klutstein et al. 2016).

DNA methylation, the most studied epigenetic mechanism, is a biochemical process where a methyl group is added to DNA nucleotides and, in mammals it typically occurs at cytosines in a $\mathrm{CpG}$ dinucleotide. DNA methylation may have a role in the control of gene expression by acting on regulatory elements. Cancer cells often show hypermethylation of the promoter region of specific genes and hypomethylation of the promoter region of repetitive elements, including long interspersed nuclear elements (LINE-1s or L1s) (Klutstein et al. 2016; Cruickshanks et al. 2013; Schulz 2006).

L1 elements constitute approximately $17 \%$ of the human genome. A full length L1 element is about $6 \mathrm{~kb}$ and consists of a 5' untranslated region (5'UTR) with sense and antisense promoter activity, two open reading frames (ORF1 and ORF2), encoding proteins involved in retrotransposition and $3^{\prime}$ untranslated region (3'UTR) with polyadenylation site. Recently, an additional ORF (ORF0) has been reported in the primate lineage and it has been suggested that it could play some positive regulatory role in the retrotransposition process (Denli et al. 2015). After transcription, the $\mathrm{L} 1$ retroelement can be inserted into another genomic site by target-primed reverse transcription (TPRT) mechanism. L1 insertion can cause insertional mutagenesis, DNA double-strand breaks, exonisation or shuffling of genetic material, resulting in genetic instability (Iskow et al. 2010).

Several studies have shown an inverse correlation between L1 expression and the methylation status of the CpG island in L1 5'-UTRs (Bourc'his and Bestor 2004). Indeed tumor cells often show both low DNA methylation levels of the L1 5'-UTR promoter region and high L1 retrotransposition activity (Schultz 2006), with consequent alterations of gene expression and genomic instability. Moreover, recent evidence suggests that alterations of the L1 promoter methylation level might be involved in several cell processes, including cell replication timing and chromatin organization (Belan 2013).

Emerging data indicate that changes in L1 5'-UTR methylation levels can be induced by environmental factors (Bollati et al. 2007; Pogribny and Beland 2013). It has been suggested that L1 5'-UTR methylation evaluation should be included in health risk assessment of environmental (Vrijheid et al. 2014; Chappell et al. 2016).

To the best of our knowledge, only one paper addressed the issue of evaluating the effects of ELF-MF exposure on DNA methylation, reporting that methylation changes occurred in mouse spermatocyte-derived GC-2 cell line under exposure to ELF-MF (Liu et al. 2015).

The aim of this study is to assess whether the exposure to ELF-MF, alone and in combination with oxidative stress $(\mathrm{OS})$, induces changes in methylation of L1 5'UTR region in human cells. A combined exposure was tested to simulate condition of real life, where the simultaneous exposure to ELF fields and other stress agents normally occurs. OS was chosen as co-stressor having been shown to affect DNA methylation (O'Hagan et al. 2011) and to contribute to tumorigenesis and tumor progression (Kryston et al. 2011; Li et al. 2015).

A pulsed magnetic field (PMF) was used since it is produced by several devices and is widely used in clinical applications. Moreover, it was shown to be biologically effective in our previous investigations (Del Re and Giorgi 2013; Del Re et al. 2012).

We used the $\mathrm{BE}(2) \mathrm{C}$ human cell line, which is representative of neuronal cell type (Biedler et al. 1978) because ELF-MF effects on neuronal cells appear interesting for the risk assessment. Indeed, epidemiological studies suggested a possible relationship between Alzheimer's disease, brain tumors and ELF-MF exposure (Qiu et al. 2004; Li et al. 2009).

\section{Materials and methods}

\section{Cell culture and treatments}

Neuroblastoma BE(2)C cells were kindly provided by Prof. Della Valle (University of Bologna, Italy), and were maintained in Dulbecco's modified Eagle's medium (DMEM, EuroClone, Milano, Italy), supplemented with $10 \%$ heatinactivated fetal bovine serum (FBS, EuroClone), $100 \mathrm{UI} /$ $\mathrm{ml}$ penicillin (Sigma, Ronkonkoma, NY, USA) and $100 \mu \mathrm{g} /$ $\mathrm{ml}$ streptomycin (Sigma), in a humidified 5\% carbon dioxide air atmosphere at $37^{\circ} \mathrm{C}$.

$24 \mathrm{~h}$ before $\mathrm{PMF} / \mathrm{Sham}$ exposure, $\mathrm{BE}(2) \mathrm{C}$ cells were seeded into $3 \mathrm{~cm}$ petri dish at the density of 75,000 cells/ dish.

$\mathrm{BE}(2) \mathrm{C}$ cells were exposed to $300 \mu \mathrm{M} \mathrm{H}_{2} \mathrm{O}_{2}$ (Sigma) for $1 \mathrm{~h}$. Control cultures were treated with equivalent volumes of distilled water. This dose has been largely used in studies dealing with oxidative stress and does not greatly affect the cell viability of our cellular model, as previously reported (Giorgi et al. 2011, 2014). 


\section{Exposure system and field characteristics}

The exposure system has been previously described (Del Re et al. 2012) and is shown in Fig. 1. It consisted of two systems, each composed by two sets of horizontal Helmholtz coils of $25 \mathrm{~cm}$ diameter, with $40(20+20)$ turns that were double-wrapped to obtain wound (active coil) or counter-wound configuration. In the counter-wound configuration, the current is the same as in the active coil but the MF is zero (sham). The coils are powered by a homemade DC current amplifier, connected with a signal generator Model 33120A (Agilent Technologies, Loveland, $\mathrm{CO}$, USA). Both the active and the sham coils were maintained in the same 5\% $\mathrm{CO}_{2}$ incubator (B-5060, Heraeus, Hanau, Germany) at a constant temperature of $37^{\circ} \mathrm{C}$, and at a sufficient distance to minimize the stray field from
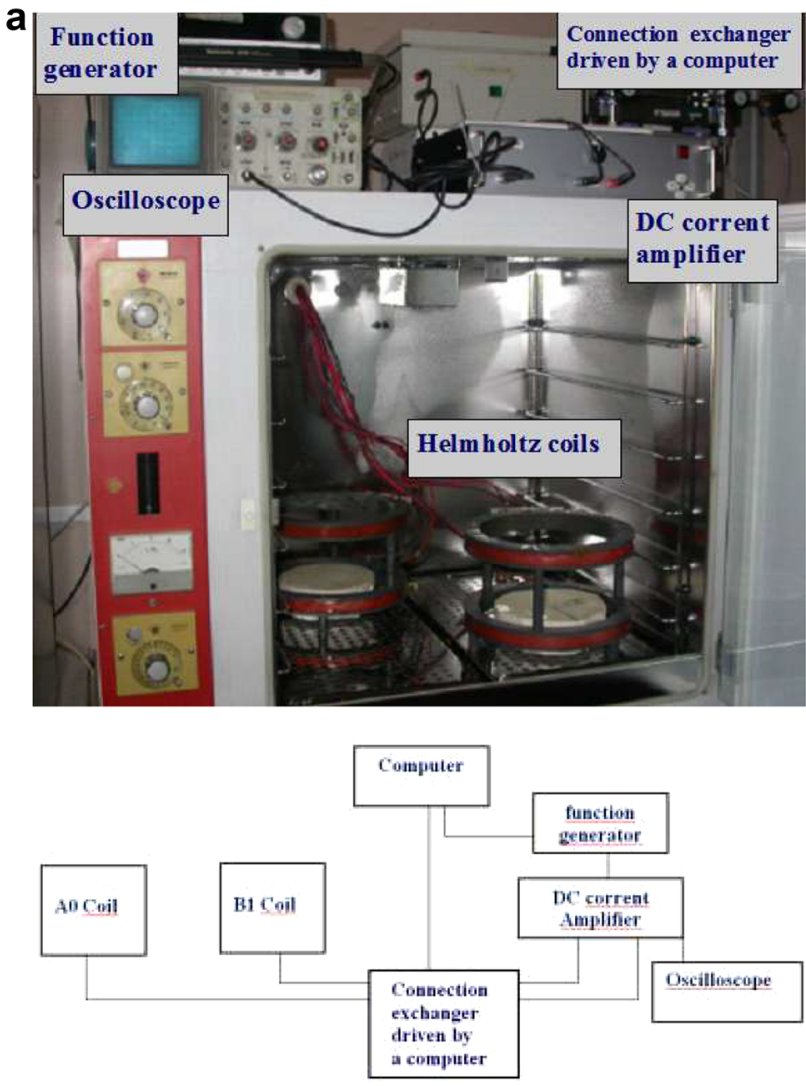

b

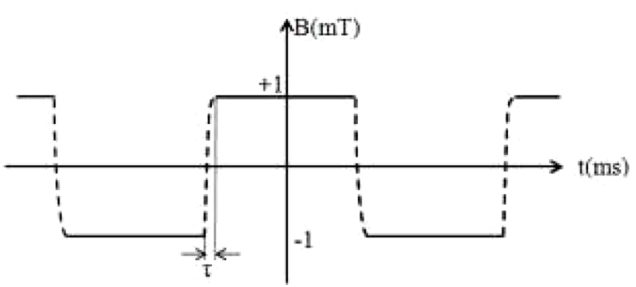

Fig. 1 xposure system (a) and PMF signal wave shape (b). The rise time $\bar{\equiv}$ the square was about $0.6 \mathrm{~ms}$ the active coil in such a way as to have in the Sham coils a magnetic field $\leq 1 / 50$ of the field in the active system. The background field within the incubator was also measured: the static component of the local magnetic field was $16.9 \mu \mathrm{T}$ (horizontal component $10.8 \mu \mathrm{T}$, vertical component $13.0 \mu \mathrm{T}$ ), the $\mathrm{AC}$ component was on the order of $0.1 \mu \mathrm{T}$, as measured with a very sensitive probe (EMDEX II, Enertech Consultants, Campbell, CA).

The system was controlled by means of a PC which, through an appropriate software and a switching system, randomly selected the active and sham coil system. All experiments were conducted in blind and only at the end of the experiments was the code decrypted. To have a field uniformity within $5 \%$, the samples were placed within a virtual cylinder (about $11 \mathrm{~cm}$ in height, and $4 \mathrm{~cm}$ in diameter), centered with respect to the coil system. A bipolar pulsed-square wave magnetic field was chosen (Fig. 1b), with an intensity 0 -peak of $1 \mathrm{mT}$, a $50-\mathrm{Hz}$ repetition frequency, and a duty cycle $50 \%$. The rise time $\tau$ of the square, from peak to peak, was about $0.6 \mathrm{~ms}$, resulting in an average rate of change of magnetic flux density of $3.3 \mathrm{~T} / \mathrm{s}$. The MF was measured by means of a Bell gaussmeter (F.W. Bell 7010, Division of Test and Measurement, Orlando, FL); the error in the magnetic flux-density values was on the order of $2 \%$.

\section{DNA extraction and sodium bisulfite treatment}

Genomic DNA was extracted by QIAmp DNA Mini Kit (QIAgen, Hilden, Germany) according to manufacturer's instructions. $1 \mu \mathrm{g}$ was treated with sodium bisulfite using the EZ methylation kit (Zymo-Research, Irvine, CA). The treatment converts unmethylated cytosine into uracil, leaving methylated cytosine unchanged. In this way, variations in the sequence are produced according to DNA methylation status of the original DNA molecule.

\section{Methylation analysis}

MassARRAY EpiTYPER technology (Sequenom) was used to quantitatively measure the methylation status of $\mathrm{CpG}$ sites within L1 5'UTR region (Accession No. X58075) (Fig. 2). $10 \mathrm{ng}$ of bisulphite-treated DNA were PCR-amplified using the following primers: forward strand primer: AGGAAGAGAGTTTATTAGGGAGTGTTAGAT AGTGGG; reverse strand primer: CAGTAATACGACTCA CTATAGGGAGAAGGCTTCTATACCCTACCCCCA AAAATAAA.

By using these primers, we evaluated DNA methylation levels of $24 \mathrm{CpG}$ units (i.e. regions containing one or multiple CpG sites), containing $28 \mathrm{CpG}$ sites (Table 1). 


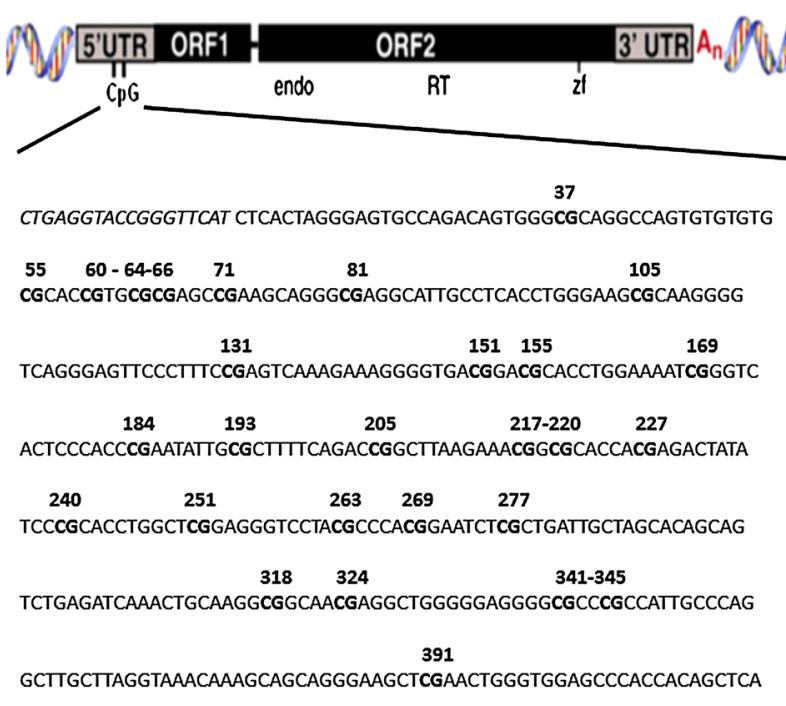

AGGAGGCCTGCCTGCCTCTGTAGGCTCCACCTCTGGGGGCAGGGCACAGA CAAACAAAAAG

Fig. 2 Schematic structure of an L1 element and CpG sites of the L1 5'UTR region. The sequence represents a 466 base pair fragment (Accession No. X58075). Numbers refer to locations of the CpG units interrogated for their methylation level by MassARRAY EpiTYPER

Table $124 \mathrm{CpG}$ units containing $28 \mathrm{CpG}$ sites of the L1 5 'UTR region

\section{Statistical analysis}

Student's $t$ test was used to evaluate differences in methylation levels. A $p$ value $<0.05$ was considered to correspond with statistical significance.

\section{Results}

To verify whether PMF exposure alone or in combination with OS would affect DNA methylation level of the L1 5'UTR region, $\mathrm{BE}(2) \mathrm{C}$ cells were exposed or sham-exposed to PMF using the exposure system shown in Fig. 1. In the first hour of exposure, samples were subjected or not to OS (hydrogen peroxide $300 \mu \mathrm{M}, 1 \mathrm{~h}$ ). After 24 and $48 \mathrm{~h}$ of exposure, DNA methylation was evaluated by MassARRAY EpiTYPER technology, which is a highly accurate and sensitive method for the quantitative analysis of DNA methylation. We focused on a part of the L1 5'UTR region which is $466 \mathrm{bp}$ in length and includes $24 \mathrm{CpG}$ units (Fig. 2). The comparison of methylation levels of all CpGs among all the samples showed that the methylation level of $10 \mathrm{CpG}$ units was modified depending on the type of treatment.

Effects of PMF exposure alone are shown in Fig. 3. After $24 \mathrm{~h}$ of PMF exposure, 3 CpGs $(37,217-220,318)$ exhibited a significantly increased methylation level as compared to the CpGs from sham exposed samples (Fig. 3a). After $48 \mathrm{~h}$ of PMF exposure no significant differences were observed at any CpGs (Fig. 3b).

Results on the effects of OS alone are shown in Fig. 4. After $24 \mathrm{~h}$ three CpGs $(184,205,277)$ exhibited significantly less methylation as compared to the CpGs from control samples (Fig. 4a). Also in this case, after 48 h no significant differences were observed at any $\mathrm{CpG}$ units (Fig. 4b).

Results about the effects of PMF exposure in combination with OS are shown in Fig. 5. After 24 h $5 \mathrm{CpG}$ units $(37,131,184,217-220,318)$ exhibited significantly less methylation as compared to the $\mathrm{CpGs}$ from samples exposed to PMF alone (Fig. 5a). After $48 \mathrm{~h}$ only $2 \mathrm{CpG}$ units $(60: 64: 66,217-220)$ showed lower methylation levels than control (PMF) (Fig. 5b).

\section{Discussion}

Epigenetic processes, including DNA methylation, are a molecular interface mediating the interaction between genome and environment. Changes in global genome methylation have been observed in association with exposure to such factors as air pollution (De Prins et al. 2013), gamma radiation (Kumar et al. 2011) low-levels of benzene
260 261 262 263 264 265

\begin{tabular}{|l|l|l|l|l|}
\hline Journal : Large 411 & Article No : 683 & Pages : 8 & MS Code : REBS-D-16-00093 & Dispatch : 28-1-2017 \\
\hline
\end{tabular}




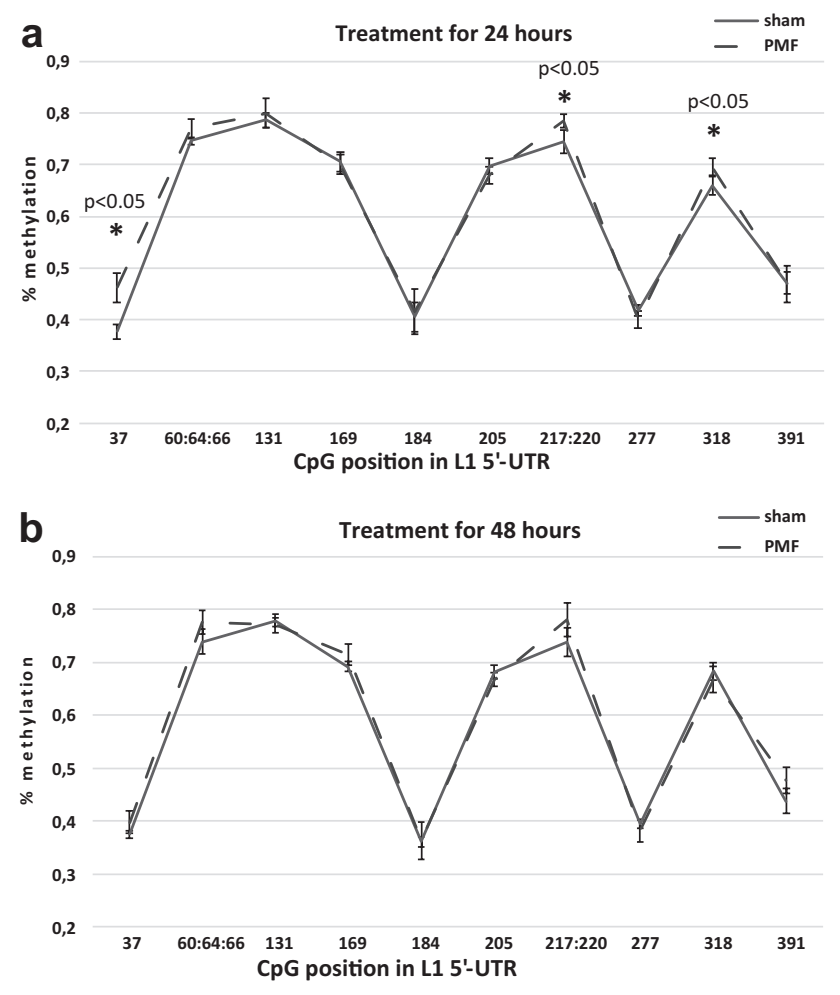

Fig. 3 CpG dinucleotide methylation percentage of L1 5'UTR region in cells exposed to PMF (dashed line) or exposed to sham (control, continuous line) for a 24 and b 48 h. Error bars represent SEM of the values obtained from three independent experiments
(Bollati et al. 2007), cigarette smoke (Liu et al. 2010), synthetic compounds such as perfluoroalkylacids (Watkins et al. 2014), various genotoxic and non-genotoxic carcinogens (Pogribny and Beland 2013) and nutritional factors (Bacalini et al. 2014). However, the effects of ELF-MF on DNA methylation in human cells has never been studied. Therefore, we analyzed the DNA methylation levels of the L1 5'UTR region, which is commonly investigated as a surrogate for global genome methylation (Yang et al. 2004), in $\mathrm{BE}(2) \mathrm{C}$ cells.

We showed that the exposure to PMF can interfere with DNA methylation inducing a slight increase in DNA methylation levels of some CpGs located in the L1 $5^{\prime}$ UTR region. Moreover, we found that OS alone induced a small and transient decrease of DNA methylation levels at some $\mathrm{CpG}$ units, whereas the combined exposures to PMF and OS induced a methylation decrease in $10 \mathrm{CpG}$ units (Fig. 5). Therefore, in the presence of OS, the slight alone, disappeared.

The relationship between ELF-MF and oxidative stress has been largely debated and it has been proposed that ELF-MF can both induce ROS production and activate antioxidants, depending on the specific conditions increase of methylation, induced by the exposure to PMF

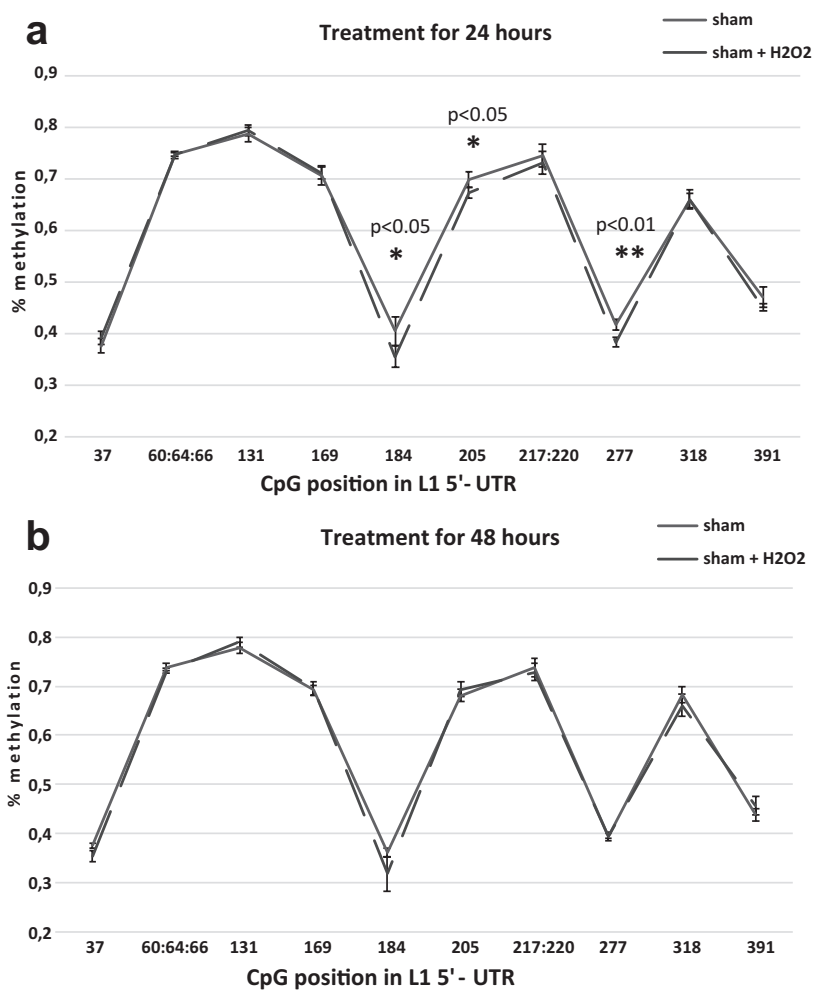

Fig. 4 CpG dinucleotide methylation percentage of L1 5'UTR region in cells subjected to oxidative stress $\left(300 \mu \mathrm{M} \mathrm{H}_{2} \mathrm{O}_{2}\right.$ for $1 \mathrm{~h}$ ) (dashed line) or distillated water (control, continuous line) after a 24 and b $48 \mathrm{~h}$ from the treatment. Error bars represent SEM of the values obtained from three independent experiments

tested (Manikonda et al. 2014; Di Loreto et al. 2009). Here, we observed that PMF synergistically contributes to OS effects. However, after $48 \mathrm{~h}$ of exposure methylation changes became undetectable. This result seems to be in line with the most recent evolutionary theories about the role of DNA methylation changes in humans (Klironomos et al. 2013; Flores et al. 2013; Giuliani et al. 2015). These theories suggested that methylation changes seem of crucial importance for rapid response to new stimuli, and in particular when new stimuli (in this case $\mathrm{PMF}+\mathrm{H} 202$ ) arise. The data suggest that the environmental change from a normal condition-more than the constant exposure itself-increase DNA methylation variability, at least at the cellular level. The molecular mechanisms involved in these changes need to be validated in future studies but we can speculate as follows. DNA methylation patterns are dynamic states resulting from a continuous balance of methylation and demethylation. The 'maintenance methyltransferase' DNMT1 mainly maintains the methylation patterns across replication cycles, while de novo DNMT3A and DNMT3B enzymes mainly introduce methyl groups into unmethylated sites (Jurkowska et al. 2011). Currently, not much is known about the effects of electromagnetic

\begin{tabular}{|l|l|l|l|l|}
\hline Journal : Large 411 & Article No : 683 & Pages : 8 & MS Code : REBS-D-16-00093 & Dispatch : 28-1-2017 \\
\hline
\end{tabular}



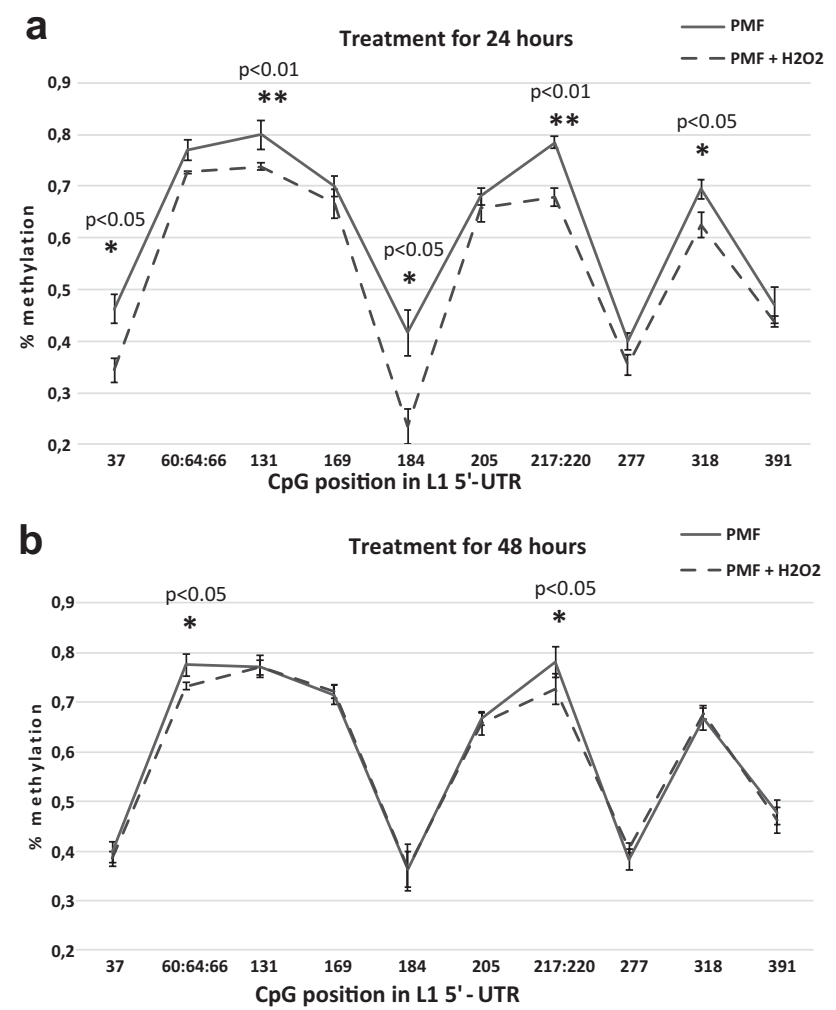

Fig. $5 \mathrm{CpG}$ dinucleotide methylation percentage of L1 5'UTR region in cells exposed to PMF and subjected to oxidative stress $(300 \mu \mathrm{M}$ $\mathrm{H}_{2} \mathrm{O}_{2}$ for $1 \mathrm{~h}$ ) (dashed line) or distillated water (control, continuous line) after a 24 and b $48 \mathrm{~h}$ from the treatment. Error bars represent SEM of the values obtained from three independent experiments

fields on these enzymes, but a recent paper suggests that DNMT1 and DNMT3B activity can be modulated by intermittent ELF-MF exposure, depending on the magnetic field intensity (Liu et al. 2015). Kloypan et al. (2015) found that OS can induce LINE-1 hypomethylation and they observed that this effect was mediated through the depletion of S-adenosylmethionine (SAM) which is the classical methyl donor for methyltrasferases.

In our model, therefore, modulation of methyltransferase could be the mechanism responsible for the observed PMF effect, according with Liu et al. (2015). In addition, depletion of SAM could be the underlying reason for the OS effect, according to Kloypan et al. (2015). Finally, in the combined exposure, the presence of OS could determine an insufficient quantity of SAM, inhibiting the methyltransferase activity and, therefore, masking the increase of methylation induced by the PMF exposure alone.

Our data stimulate two methodological considerations. The first is about the time of exposure. Most studies on the relationship between DNA methylation alterations and environmental factors are epidemiological ones, which usually do not investigate the effects of different exposure times. We analyzed two different exposure times and we found different results, showing that the effects were transient. Therefore, whenever possible, it is strongly recommended to analyze various exposure times. The second consideration is about the $\mathrm{CpG}$ sites that are affected by ELF-MF/OS exposure. The MassARRAY EpiTYPER approach allows to quantitatively evaluate DNA methylation levels of multiple adiacent CpGs, providing more detailed information with respect to other commonly used approaches, such as the COBRA (combined bisulphite restriction analysis polymerase chain reaction) assay. We analyzed $24 \mathrm{CpG}$ units and we observed that methylation changes occurred preferentially at specific $\mathrm{CpG}$. This observation is in agreement with findings by Nüsgen et al. (2015), who observed that some specific $\mathrm{CpG}$ units within 5'-UTR L1 region are more prone to be subjected to methylation modifications. Our data suggest that it is important to analyse as many $\mathrm{CpG}$ sites as possible, since we do not known which sites are sensitive in each cell type and eventually affect gene transcription.

Emerging evidences reveal that microvesicles represent an important mechanism of cell to cell communication and that they can be involved in epigenetic processes including DNA methylation (Qian et al. 2015). Recently, it has been reported that microvesicles are released from cells upon activation by various stimuli including radiation (Jella et al. 2014) and ELF-MF exposure (Stratton et al. 2013). This aspect should be investigated, to verify whether it could be involved in the epigenetic alterations which we observed.

In conclusion, our results suggest that only some $\mathrm{CpG}$ units within L1 5'-UTR region could be subjected to methylation modification by PMF and OS exposure and that these alterations are, in any case, transient. The biological relevance of these transient variations of DNA methylation levels needs to be elucidated; they are at the forefront of important mechanisms of what is generally called "epigenetic stress". We hypothesize that these variations can explain some conflicting results obtained until now in in vitro cell systems after ELF exposure. Further studies are needed to clarify this point and to elucidate the epigenetic effect of ELF-MFs alone and in the presence of OS, also considering different cell types and exposure scenarios.

Acknowledgements This work was supported by RFO (Ricerca Fondamentale Orientata, Oriented Fundamental Research) grants from the University of Bologna to BDR and to MC. Funds were also obtained by Fondazione Pallotti to PG and MC.

\section{Compliance with ethical standards}

Conflict of interest The authors report no conflicts of interests. The authors alone are responsible for the content and writing of the paper.

\begin{tabular}{|l|l|l|l|l|}
\hline Journal : Large 411 & Article No : 683 & Pages : 8 & MS Code : REBS-D-16-00093 & Dispatch : 28-1-2017 \\
\hline
\end{tabular}




\section{References}

Bacalini MG, Friso S, Olivieri F, Pirazzini C, Giuliani C, Capri M, Santoro A, Franceschi C, Garagnani P (2014) Present and future of anti-ageing epigenetic diets. Mech Ageing Dev 136-137:101-115

Belan E (2013) LINEs of evidence: noncanonical DNA replication as an epigenetic determinant. Biol Direct 8:22. doi:10.1186/1745-6150-8-22

Biedler JL, Roffler-Tarlov S, Schachner M, Freedman LS (1978) Multiple neurotransmitter synthesis by human neuroblastoma cell lines and clones. Cancer Res 38:3751-3757

Bollati V, Baccarelli A, Hou L, Bonzini M, Fustinoni S, Cavallo D, Byun HM, Jiang J, Marinelli B, Pesatori AC, Bertazzi PA, Yang AS (2007) Changes in DNA methylation patterns in subjects exposed to low-dose benzene. Cancer Res 67:876-880

Bourc'his D, Bestor TH (2004) Meiotic catastrophe and retrotransposon reactivation in male germ cells lacking Dnmt3L. Nature 431:96-99

Chappell G, Pogribny IP, Guyton KZ, Rusyn I (2016) Epigenetic alterations induced by genotoxic occupational and environmental human chemical carcinogens: a systematic literature review. Mutat Res Rev Mutat Res 768:27-45. doi:10.1016/j. mrrev.2016.03.004

Cruickshanks HA, Vafadar-Isfahani N, Dunican DS, Lee A, Sproul D, Lund JN, Meehan RR, Tufarelli C (2013) Expression of a large LINE-1-driven antisense RNA is linked to epigenetic silencing of the metastasis suppressor gene TFPI-2 in cancer. Nucleic Acids Res 41:6857-6869

De Prins S, Koppen G, Jacobs G, Dons E, Van de Mieroop E, Nelen V, Fierens F, IntPanis L, De Boever P, Cox B, Nawrot TS, Schoeters $G$ (2013) Influence of ambient air pollution on global DNA methylation in healthy adults: a seasonal follow-up. Environ Int 59:418-424

Del Re B, Giorgi G (2013) Cell-host, LINE and environment: three players in search of a balance. Mob Genet Elem 3:1-4e24040. doi: $10.4161 / \mathrm{mge} .24040$

Del Re B, Marcantonio P, Gavoçi E, Bersani F, Giorgi G (2012) Assessing LINE-1 retrotransposition activity in neuroblastoma cells exposed to extremely low-frequency pulsed magnetic fields. Mutat Res 749(1-2):76-81

Denli AM, Narvaiza I, Kerman B, Pena M, Benner C, Marchetto MC, Diedrich JK, Aslanian A, Ma J, Moresco JJ, Moore L, Hunter T, Saghatelian A, Gage FH (2015) Primate-specific ORF0 contributes to retrotransposon-mediated diversity. Cell 163:583-593. doi:10.1016/j.cell.2015.09.025

Di Loreto S, Falone S, Caracciolo V, Sebastiani P, D'Alessandro A et al (2009) Fifty hertz extremely low-frequency magnetic field exposure elicits redox and trophic response in rat-cortical neurons. J Cell Physiol 219:334-343. doi:10.1002/jcp.21674

Flores KB, Wolschin F, Amdam GV (2013) The role of methylation of DNA in environmental adaptation. Integr Comp Biol 53:359372. doi:10.1093/icb/ict019

Giorgi G, Marcantonio P, Del Re B (2011) LINE-1 retrotransposition in human neuroblastoma cells is affected by oxidative stress. Cell Tissue Res 346:383-391. doi:10.1007/s00441-011-1289-0

Giorgi G, Lecciso M, Capri M, Lukas Yani S, Virelli A, Bersani F, Del Re B (2014) An evaluation of genotoxicity in human neuronal-type cells subjected to oxidative stress under an extremely low frequency pulsed magnetic field. Mutat Res Genet Toxicol Environ Mutagen 775-776:31-37

Giuliani C, Bacalini MG, Sazzini M, Pirazzini C, Franceschi C, Garagnani P, Luiselli D (2015) The epigenetic side of human adaptation: hypotheses, evidences and theories. Ann Hum Biol 42:1-9. doi:10.3109/03014460.2014.961960
IARC Working Group on the Evaluation of Carcinogenic Risks to Humans (2002) Non-ionizing radiation, Part 1: static and extremely low-frequency (ELF) electric and magnetic fields. IARC Monogr Eval Carcinog Risks Hum 80:1-395

Iskow RC, McCabe MT, Mills RE, Torene S, Pittard WS, Neuwald AF, Van Meir EG, Vertino PM, Devine SE (2010) Natural mutagenesis of human genomes by endogenous retrotransposons. Cell 141:1253-1261

Jella KK, Rani S, O’Driscoll L, McClean B, Byrne HJ, Lyng FM (2014) Exosomes are involved in mediating radiation induced bystander signaling in human keratinocyte cells. Radiat Res 181:138-145. doi:10.1667/RR13337.1

Jurkowska RZ, Jurkowski TP, Jeltsch A (2011) Structure and function of mammalian DNA methyltransferases. Chembiochem $12: 206-222$

Klironomos FD, Berg J, Collins S (2013) How epigenetic mutations can affect genetic evolution: model and mechanism. Bioessays 35:571-578. doi:10.1002/bies.201200169

Kloypan C, Srisa-art M, Mutirangura A, Boonla C (2015) LINE-1 hypomethylation induced by reactive oxygen species is mediated via depletion of S-adenosylmethionine. Cell Biochem Funct 33:375-385. doi:10.1002/cbf.3124

Klutstein M, Nejman D, Greenfield R, Cedar H (2016) DNA methylation in cancer and aging. Cancer Res 76:3446-3450. doi:10.1158/0008-5472.CAN-15-3278

Kryston TB, Georgiev AB, Pissis P, Georgakilas AG (2011) Role of oxidative stress and DNA damage in human carcinogenesis. Mutat Res 711:193-201. doi:10.1016/j.mrfmmm.2010.12.016

Kumar A, Rai PS, Upadhya R, Vishwanatha KS, K (2011) $\gamma$-radiation induces cellular sensitivity and aberrant methylation in human tumor cell lines. Int J Radiat Biol 87:10861096. doi:10.3109/09553002.2011.605417

Li P, McLaughlin J, Infante-Rivard C (2009) Maternal occupational exposure to extremely low frequency magnetic fields and the risk of brain cancer in the offspring. Cancer Causes Control 20:945-955. doi:10.1007/s10552-009-9311-5

Li Z, Doho G, Zheng X, Jella KK, Li S, Wang Y, Dynan WS (2015) Co-culturing with high-charge and energy particle irradiated cells Increases mutagenic joining of enzymatically induced DNA double-strand breaks in nonirradiated Cells. Radiat Res 184:249-258. doi:10.1667/RR14092.1

Liu F, Killian JK, Yang M, Walker RL, Hong JA, Zhang M, Davis S, Zhang Y, Hussain M, Xi S, Rao M, Meltzer PA, Schrump DS (2010) Epigenomic alterations and gene expression profiles in respiratory epithelia exposed to cigarette smoke condensate. Oncogene 29(25):3650-3664

Liu Y, Liu WB, Liu KJ, Ao L, Zhong JL, Cao J, Liu JY (2015) Effect of $50 \mathrm{~Hz}$ extremely low-frequency electromagnetic fields on the DNA methylation and DNA methyltransferases in mouse spermatocyte-derived cell line GC-2. Biomed Res Int 2015:237183. doi:10.1155/2015/237183

Manikonda PK, Rajendra P, Devendranath D, Gunasekaran B, Channakeshava, Aradhya SR, Sashidhar RB, Subramanyam C (2014) Extremely low frequency magnetic fields induce oxidative stress in rat brain. Gen Physiol Biophys 33:81-90. doi:10.4149/gpb_2013059

Marcantonio P, Del Re B, Franceschini A, Capri M, Lukas S, Bersani F, Giorgi G (2010) Synergic effect of retinoic acid AQ and extremely low frequency magnetic field exposure on human neuroblastoma cell line $\mathrm{BE}(2) \mathrm{C}$. Bioelectromagnetics 31:425-433

Nüsgen N, Goering W, Dauksa A, Biswas A, Jamil MA, Dimitriou I, Sharma A, Singer H, Fimmers R, Fröhlich H, Oldenburg J, Gulbinas A, Schulz WA, El-Maarri O (2015) Inter-locus as well as intra-locus heterogeneity in LINE-1 promoter methylation in common human cancers suggests selective demethylation

\begin{tabular}{|l|l|l|l|l|}
\hline Journal : Large 411 & Article No : 683 & Pages : 8 & MS Code : REBS-D-16-00093 & Dispatch : 28-1-2017 \\
\hline
\end{tabular}


pressure at specific CpGs. Clin Epigenetics 7:17. doi:10.1186/ s13148-015-0051-y

O'Hagan HM, Wang W, Sen S, Destefano Shields C, Lee SS, Zhang YW, Clements EG, Cai Y, Van Neste L, Easwaran H, Casero RA, Sears CL, Baylin SB (2011) Oxidative damage targets complexes containing DNA methyltransferases, SIRT1, and polycomb members to promoter CpG Islands. Cancer Cell 20:606619. doi:10.1016/j.ccr.2011.09.012

Pogribny IP, Beland F (2013) DNA methylome alterations in chemical carcinogenesis. Cancer Lett 334:39-45

Qian Z, Shen Q, Yang X, Qiu Y, Zhang W (2015) The role of extracellular vesicles: an epigenetic view of the cancer microenvironment. Biomed Res Int 2015:649161. doi:10.1155/2015/649161

Qiu C, Fratiglioni L, Karp A, Winblad B, Bellander T (2004) Occupational exposure to electromagnetic fields and risk of Alzheimer's disease. Epidemiology 15:687-694

Schulz WA (2006) L1 retrotransposons in human cancers. J Biomed Biotechnol 2006(1):83672

Speek M (2001) Antisense promoter of human L1 retrotransposon dr $\bar{\equiv}$ ranscription of adjacent cellular genes. Mol Cell Biol 21:1973-1985

Stratton D, Lange S, Inal JM (2013) Pulsed extremely low-frequency magnetic fields stimulate microvesicle release from human monocytic leukaemia cells. Biochem Biophys Res Commun 430:470-475. doi:10.1016/j.bbrc.2012.12.012

Vijayalaxmi TJ, Prihoda (2009) Genetic damage in mammalian somatic cells exposed to extremely low frequency electro-magnetic fields: a meta-analysis of data from 87 publications (19902007). Int J Radiat Biol 85:196-213

Vrijheid M, Slama R, Robinson O, Chatzi L, Coen M, van den Hazel P, Thomsen C, Wright J, Athersuch TJ, Avellana N, Basagaña X, Brochot C, Bucchini L, Bustamante M, Carracedo A, Casas M, Estivill X, Fairley L, van Gent D, Gonzalez JR, Granum B, Gražulevičienė R, Gutzkow KB, Julvez J, Keun HC, Kogevinas M, McEachan RR, Meltzer HM, Sabidó E, Schwarze PE, Siroux V, Sunyer J, Want EJ, Zeman F, Nieuwenhuijsen MJ (2014) The human early-life exposome (HELIX): project rationale and design. Environ Health Perspect 122(6):535-544

Watkins DJ, Wellenius GA, Butler RA, Bartell SM, Fletcher T, Kelsey KT (2014) Associations between serum perfluoroalkyl acids and LINE-1 DNA methylation. Environ Int 63:71-76 A simple method for estimating global DNA methylation usi bisulfite PCR of repetitive DNA elements. Nucleic Acids Res AQ2 32:e38

\begin{tabular}{|l|l|l|l|l|}
\hline Journal : Large 411 & Article No : 683 & Pages : 8 & MS Code : REBS-D-16-00093 & Dispatch : 28-1-2017 \\
\hline
\end{tabular}




\begin{tabular}{|l|l|}
\hline Journal: & $\mathbf{4 1 1}$ \\
Article: & $\mathbf{6 8 3}$ \\
\hline
\end{tabular}

\section{包 Springer}

the language of science

\section{Author Query Form}

\section{Please ensure you fill out your response to the queries raised below and return this form along with your corrections}

Dear Author

During the process of typesetting your article, the following queries have arisen. Please check your typeset proof carefully against the queries listed below and mark the necessary changes either directly on the proof/online grid or in the 'Author's response' area provided below

\begin{tabular}{|l|l|l|}
\hline Query & Details Required & Author's Response \\
\hline AQ1 & $\begin{array}{l}\text { Author: References "Marcantonio et al. (2010) and Speek (2001)" are given in list but } \\
\text { not cited in text. Please cite in text or delete from list. }\end{array}$ & $\begin{array}{l}\text { Author: Fig1 - Figure is poor in quality as its labels are not readable. Please supply a } \\
\text { new version of the said figure with legible labels preferably in .eps, .tiff or .jpeg format } \\
\text { with 600 dpi resolution. }\end{array}$ \\
\hline AQ2 & $\begin{array}{l}\text { Author: Fig1 - Figure is poor in quality as its labels are not readable. Please supply a } \\
\text { new version of the said figure with legible labels preferably in .eps, .tiff or .jpeg format } \\
\text { with 600 dpi resolution. }\end{array}$ & \\
\hline
\end{tabular}

